\title{
Sistem Pendukung Keputusan dalam Menenetukan Calon (Tailor) Penjahit di Ranhouse Medan dengan Menggunakan Metode AggregatedSum Product Assesment
}

\author{
*Antiani, Puji Sari Ramadhan, Suardi Yakub \\ Program Studi Sistem Komputer, STMIK Triguna Dharma \\ Jl. A.H Nasution No.73 Medan, Indonesia, 20142
}

\begin{abstract}
Abstrak
Keberhasilan sebuah perusahaan dilihat dari karyawan yang memiliki keterampilan dan bakat. Untuk menunjang keberhasilan tersebut perusahaan harus lebih selektif lagi dalam memilih karyawan, salah satunya adalah pemilihan Penjahit. Tujuan Utama dalam proses menentukan calon Tailor (Penjahit) adalah untuk menentukan Tailor (Penjahit) yang memiliki keahlian dalam memenuhi kebutuhan perusahaan maupun permintaan para konsumen.

Dari uraian diatas perlu dibuat sebuah sistem pendukung keputusan dalam menentukan calon Tailor (Penjahit) di Ranhouse Medan dengan menggunakan metode Weighted Aggregated Sum Product Assesment (WASPAS). Sistem ini nantinya akan membantu dalam pengambilan keputusan menentukan calon Tailor (Penjahit) dengan cepat dan tepat.

Hasil penelitian diharapkan dapat membantu pihak Ranhouse Medan dalam pengambilan keputusan pemilihan Calon Tailor(Penjahit) yang dilakukan lebih objektif sesuai dengan kriteria yang ditentukan oleh Ranhouse Medan.
\end{abstract}

Kata kunci : Tailor (Penjahit), Sistem Pendukung Keputusan, Waspas

\begin{abstract}
The success of a company is seen from employees who have skills and talents. To support this success, the company must be more selective in choosing employees, one of which is the selection of tailors. The main objective in the process of determining a tailor candidate (tailor) is to determine a tailor who has expertise in meeting company needs and consumer demands.

From the description above, it is necessary to make a decision support system in determining the tailor candidates (tailors) at Ranhouse Medan using the Weighted Aggregated Sum Product Assessment (WASPAS) method. This system will later assist in making decisions quickly and precisely to determine the tailor candidates.

The results of the research are expected to help Ranhouse Medan in making more objective decisions on the selection of Tailor Candidates in accordance with the criteria determined by Ranhouse Medan.
\end{abstract}

Keywords: Tailor (Tailor), Decision Support System, Waspas

\section{PENDAHULUAN}


Tailor artinya penjahit, tukang jahit. Orang yang bekerja menjahit pakaian disebut dengan penjahit [1]. Dalam setiap bidang usaha pasti memiliki karyawan, seperti halnya menjadi seorang penjahit. Seperti halnya dalam pemesanan maupun penempahan busana yang tidak sesuai, salah satunya adalah hasil busana yang diharapkan tidak sesuai yang diinginkan para konsumen. Hal tersebut dikarenakan kurangnya bakat maupun keterampilan yang dimiliki. Dengan itu perusahaan maupun bidang usaha harus lebih teliti dan selektif dalam menentukan calon tailor (penjahit) dengan menyesuaikan kriteria-kriteria yang dibutuhkan sesuai dengan prosedur perusahaan. Hal ini bertujuan untuk peningkatan maupun kemajuan sebuah perusahaan maupun bidang usaha dalam mencari calon tailor (penjahit) yang memiliki bakat.

Dalam hal memilih calon tailor (penjahit) pada Ranhouse Medan diperlukan beberapa kriteria dalam pemilihan calon tailor (penjahit) dimana hasil pemilihan tersebut mendapatkan keputusan yang akurat sesuai dengan harapan.

Untuk memberikan keputusan yang lebih baik pada Ranhouse Medan, maka dibutuhkan sebuah sistem agar dapat memberikan solusi dalam menentukan calon tailor (penjahit) dari beberapa alternatif. Untuk mengatasi permasalahan dalam menentukan calon tailor (penjahit), maka dapat diselesaikan dengan menggunakan Sistem Pendukung Keputusan (SPK). Sistem Pendukung Keputusan (SPK) merupakan sistem informasi dapat memecahkan sebuah masalah dalam situasi yang semiterstruktur dan situasi yang tidak terstruktur. Agar tujuan dari SPK ini dapat tercapai dengan baik maka dibantu dengan menggunakan salah satu metode dalam Sistem Pendukung Keputusan yaitu, metode weighted Aggregated Sum Product Assesment yang mampu membantu pengambil keputusan dalam menentukan calon tailor (penjahit).

\section{KAJIAN PUSTAKA}

\subsection{Sistem Pendukung Keputusan}

Sistem Pendukung Keputusan merupakan sistem informasi interaktif yang menyediakan informasi, pemodelan, dan pemanipulasian data. Sistem itu digunakan untuk membantu pengambilan keputusan dalam situasi yang semi terstruktur dan situasi yang tidak terstruktur dimana tidak seorangpun tahu secara pasti bagaiman keputusan seharusnya dibuat [2].

Secara umum sistem pendukung keputusan didefinisikan sebagai bagian dari sistem informasi berbasis komputer termasuk sistem berbasis pengetahuan atau manajemen pengetahuan yang dipakai untuk mendukung pengambilan keputusan dalam suatu organisasi atau perusahaan[3].

\subsection{Metode Weighted Aggregated Asum Product Assesment (WASPAS)}

Metode Weighted Aggregated Sum Product Assesment (WASPAS) merupakan metode gabungan yang terdiri dari metode WP dan metode SAW, metode WASPAS ini diharapkan dapat memberikan hasil yang lebih baik dalam membantu penentuan sistem pendukung keputusan [4].

Berikut langkah-langkah Metode WASPAS sebagai berikut [5] :

1. Menentukan Normalisasi matriks dalam pengambilan keputusan

$$
\mathrm{x}=\left[\begin{array}{lll}
x_{11} & x_{12} & x_{1 n} \\
x_{21} & x_{22} & x_{2 n} \\
x_{m i} & x_{m 2} & x_{m n}
\end{array}\right]
$$

2. Jika nilai maksimal dan nilai minimal telah ditentukan maka persamaan sebagai berikut : Kriteria Benefit

$$
\mathrm{X}_{\mathrm{ij}}=\frac{x_{i j}}{\max i x_{i j}}
$$


Kriteria Cost

$$
\mathrm{X}_{\mathrm{ij}}=\frac{\min n_{i x i j}}{x i j}
$$

3. Menghitung Nilai Normalisasi Matriks dan Bobot WASPAS dalam Pengambilan Keputusan

$$
Q i=0,5 \sum_{j=1}^{n} X i j w+0,5 \prod_{j=1}^{n}(x i j)^{w j}
$$

\section{Perangkingan}

\subsection{Tailor (Penjahit)}

Tailor artinya penjahit, tukang jahit. Orang yang bekerja menjahit pakaian disebut dengan penjahit. Dan dalam kegiatan menjahit ada banyak jenis menjahit yaitu menjahit baju, sepatu, tas, merajut, menyulam, membordir [1]. Penjahit adalah sebuah pekerjaan yang sehari-harinya menjahit pakaian, tas, dll.

\section{Metodologi Penelitian}

\subsection{Metode Penelitian}

Dalam proses menganalisa dilakukan beberapa langkah untuk mendapatkan data, seperti dengan melakukan teknik pengumpulan data yaitu:

1. Observasi

Melakukan kunjungan langsung ke Ranhouse Medan dalam menganalisa permasalahan pada pemilihan calon penjahit. Dari permasalahan tersebut dapat dirumuskan apa saja yang perlu dipersiapkan dan bagaimana cara menyelesaikan permasalahan tersebut.

\section{Wawancara}

Melakukan wawancara langsung dengan melakukan tanya jawab langsung dengan narasumber ataupun pemilik di Ranhouse Medan. Salah satunya adalah mengajukan pertanyaan terkait dengan permasalahan yang diangkat dalam menentukan calon penjahit di Ranhouse, bagaimana sistem yang berjalan sebelumnya dalam menntukan calon penjahit dan kriteria-kriteria apa saja dalam penentuan untuk menjadi seorang penjahit.

Berikut ini adalah penerapan metode WASPAS (Weighted Aggregated Sum Product Assessment)dalam menentukan calon Tailor (Penjahit) di Ranhouse Medan dengan perhitungan dapat dilihat pada contoh dibawah ini:

\begin{tabular}{|c|c|c|c|c|c|c|}
\hline $\begin{array}{l}\mathbf{N} \\
0\end{array}$ & $\begin{array}{c}\text { Nama } \\
\text { Pelamar }\end{array}$ & Pendidikan & $\begin{array}{c}\text { Kemampuan } \\
\text { Membuat } \\
\text { Pola }\end{array}$ & $\begin{array}{c}\text { Pengala } \\
\text { man } \\
\text { Kerja }\end{array}$ & $\begin{array}{c}\text { Penguasaan } \\
\text { Teknik } \\
\text { Menjahit }\end{array}$ & $\begin{array}{c}\text { Penggunaan Mesin } \\
\text { Jahit }\end{array}$ \\
\hline 1 & $\begin{array}{l}\text { Yulinda } \\
\text { Sari }\end{array}$ & $\begin{array}{l}\text { SD + Kursus } \\
\text { Menjahit }\end{array}$ & $\begin{array}{c}\text { Mampu } \\
\text { Membuat } 1 \\
\text { Pola }\end{array}$ & $\begin{array}{c}\text { Diatas } 5 \\
\text { Tahun }\end{array}$ & $\begin{array}{c}\text { Menguasai } 1 \\
\text { Teknik } \\
\text { Menjahit }\end{array}$ & $\begin{array}{c}\text { Mampu } \\
\text { Menggunakan } 1 \\
\text { Mesin Jahit }\end{array}$ \\
\hline 2 & $\begin{array}{c}\text { Asyifa } \\
\text { Sholatul }\end{array}$ & $\begin{array}{c}\text { SMP + Kursus } \\
\text { Menjahit }\end{array}$ & $\begin{array}{c}\text { Mampu } \\
\text { Membuat } 3 \\
\text { Pola }\end{array}$ & $\begin{array}{c}0-1 \\
\text { Tahun }\end{array}$ & $\begin{array}{c}\text { Menguasai } 2 \\
\text { Teknik } \\
\text { Menjahit }\end{array}$ & $\begin{array}{c}\text { Mampu } \\
\text { Menggunakan } 1 \\
\text { Mesin Jahit }\end{array}$ \\
\hline 3 & $\begin{array}{c}\text { Selia } \\
\text { Jurius }\end{array}$ & $\begin{array}{l}\text { SMK Tata } \\
\text { Busana }\end{array}$ & $\begin{array}{c}\text { Mampu } \\
\text { Membuat } 4 \\
\text { Pola }\end{array}$ & $\begin{array}{c}\text { Diatas } \\
1-2 \\
\text { Tahun } \\
\end{array}$ & $\begin{array}{c}\text { Menguasai } 3 \\
\text { Teknik } \\
\text { Menjahit }\end{array}$ & $\begin{array}{c}\text { Mampu } \\
\text { Menggunakan } 3 \\
\text { Mesin Jahit }\end{array}$ \\
\hline
\end{tabular}

Tabel 1. Tabel Data Primer Calon Penjahit

J-SISKO TECH Vol. 3, No. 2 Juli , 2020 : 12-24 


\begin{tabular}{|c|c|c|c|c|c|c|}
\hline 4 & $\begin{array}{l}\text { Ayundari } \\
\text { Nasution }\end{array}$ & $\begin{array}{c}\text { SMK Tata } \\
\text { Busana }\end{array}$ & $\begin{array}{c}\text { Mampu } \\
\text { Membuat } 4 \\
\text { Pola }\end{array}$ & $\begin{array}{l}\text { Diatas } \\
1-2 \\
\text { Tahun }\end{array}$ & $\begin{array}{c}\text { Menguasai } 4 \\
\text { Teknik } \\
\text { Menjahit }\end{array}$ & $\begin{array}{c}\text { Mampu } \\
\text { Menggunakan } 3 \\
\text { Mesin Jahit }\end{array}$ \\
\hline 5 & Juraiya & $\begin{array}{c}\text { SMK Tata } \\
\text { Busana }\end{array}$ & $\begin{array}{c}\text { Mampu } \\
\text { Membuat } 4 \\
\text { Pola }\end{array}$ & $\begin{array}{l}\text { Diatas } \\
2-3 \\
\text { Tahun }\end{array}$ & $\begin{array}{c}\text { Menguasai } 4 \\
\text { Teknik } \\
\text { Menjahit }\end{array}$ & $\begin{array}{c}\text { Mampu } \\
\text { Menggunakan } 4 \\
\text { Mesin Jahit }\end{array}$ \\
\hline 6 & $\begin{array}{l}\text { Zuliana } \\
\text { Hasanah } \\
\text { Sari }\end{array}$ & $\begin{array}{c}\text { SMA + Kursus } \\
\text { Menjahit }\end{array}$ & $\begin{array}{c}\text { Mampu } \\
\text { Membuat } 4 \\
\text { Pola }\end{array}$ & $\begin{array}{c}\text { Diatas } 5 \\
\text { Tahun }\end{array}$ & $\begin{array}{c}\text { Menguasai } 4 \\
\text { Teknik } \\
\text { Menjahit }\end{array}$ & $\begin{array}{c}\text { Mampu } \\
\text { Menggunakan } 3 \\
\text { Mesin Jahit }\end{array}$ \\
\hline 7 & $\begin{array}{c}\text { Rika } \\
\text { Situmean } \\
\mathrm{g}\end{array}$ & $\begin{array}{c}\text { SMK Tata } \\
\text { Busana }\end{array}$ & $\begin{array}{c}\text { Mampu } \\
\text { Membuat } 3 \\
\text { Pola }\end{array}$ & $\begin{array}{l}\text { Diatas } \\
2-3 \\
\text { Tahun }\end{array}$ & $\begin{array}{c}\text { Menguasai } 2 \\
\text { Teknik } \\
\text { Menjahit }\end{array}$ & $\begin{array}{c}\text { Mampu } \\
\text { Menggunakan } 4 \\
\text { Mesin Jahit }\end{array}$ \\
\hline 8 & $\begin{array}{l}\text { Meliyana } \\
\text { Panjaitan }\end{array}$ & $\begin{array}{c}\text { SMA + Kursus } \\
\text { Menjahit }\end{array}$ & $\begin{array}{c}\text { Mampu } \\
\text { Membuat } 4 \\
\text { Pola }\end{array}$ & $\begin{array}{l}\text { Diatas } \\
3-4 \\
\text { Tahun }\end{array}$ & $\begin{array}{c}\text { Menguasai } 2 \\
\text { Teknik } \\
\text { Menjahit }\end{array}$ & $\begin{array}{c}\text { Mampu } \\
\text { Menggunakan } 3 \\
\text { Mesin Jahit }\end{array}$ \\
\hline 9 & $\begin{array}{l}\text { Adelia } \\
\text { Santika }\end{array}$ & $\begin{array}{c}\text { SMA + Kursus } \\
\text { Menjahit }\end{array}$ & $\begin{array}{c}\text { Mampu } \\
\text { Membuat } 3 \\
\text { Pola }\end{array}$ & $\begin{array}{l}\text { Diatas } \\
1-2 \\
\text { Tahun }\end{array}$ & $\begin{array}{c}\text { Menguasai } 3 \\
\text { Teknik } \\
\text { Menjahit }\end{array}$ & $\begin{array}{c}\text { Mampu } \\
\text { Menggunakan } 3 \\
\text { Mesin Jahit }\end{array}$ \\
\hline $\begin{array}{l}1 \\
0\end{array}$ & $\begin{array}{c}\text { Mayra } \\
\text { Septiana }\end{array}$ & SMA & Tidak Mampu & $\begin{array}{l}0-1 \\
\text { Tahun }\end{array}$ & $\begin{array}{c}\text { Menguasai } 1 \\
\text { Teknik } \\
\text { Menjahit }\end{array}$ & Tidak Mampu \\
\hline
\end{tabular}

Tabel 2. Tabel Sub Kriteria

\begin{tabular}{|c|c|c|}
\hline No & Nama Kriteria & Sub Kriteria \\
\hline \multirow[t]{5}{*}{1} & \multirow[t]{5}{*}{ Pendidikan } & 1. SMK Tata Busana \\
\hline & & 2. SMP + Kursus Menjahit \\
\hline & & 3. SMA + Kursus Menjahit \\
\hline & & 4. SD + Kursus Menjahit \\
\hline & & 5. SMA \\
\hline \multirow[t]{5}{*}{2} & \multirow[t]{5}{*}{ Kemampuan Membuat Pola } & 1. Pola Konstruksi \\
\hline & & 2. Pola Jadi \\
\hline & & 3. Pola Draping \\
\hline & & 4. Pola Diatas Kain \\
\hline & & 5. Tidak Ada \\
\hline \multirow[t]{5}{*}{3} & \multirow[t]{5}{*}{ Pengalaman Kerja } & 1. $0-1$ Tahun \\
\hline & & 2. Diatas 1 - 2 Tahun \\
\hline & & 3. Diatas 2 - 3 Tahun \\
\hline & & 4. Diatas 3 - 4 Tahun \\
\hline & & 5. Diatas 5 Tahun \\
\hline \multirow[t]{5}{*}{4} & \multirow[t]{5}{*}{ Penguasaan Teknik Menjahit } & 1. Tusuk Dasar Menjahit \\
\hline & & 2. Kampuh Dasar (Menggabungkan) \\
\hline & & 3. Teknik Menjahit Belahan Busana \\
\hline & & 4. Teknik Menjahit Bagian-Bagian Busana \\
\hline & & 5. Tidak Ada \\
\hline \multirow[t]{3}{*}{5} & \multirow[t]{3}{*}{ Penggunaan Mesin Jahit } & 1. Mesin Jahit Standard \\
\hline & & 2. Mesin Jahit Singer \\
\hline & & $\begin{array}{l}\text { 3. Mesin Jahit Janome Untuk Lubang } \\
\text { Kancing }\end{array}$ \\
\hline
\end{tabular}




\begin{tabular}{|l|l|l|}
\hline & & $4 . \quad$ Mesin Jahit Obras Pegasus \\
& 5. Tidak Ada \\
\hline
\end{tabular}

Tabel 3. Keterangan Kriteria

\begin{tabular}{|c|l|c|c|c|}
\hline Kriteria & \multicolumn{1}{|c|}{ Keterangan kriteria } & Bobot & $\begin{array}{c}\text { Normalisasi } \\
\text { Bobot }\end{array}$ & $\begin{array}{c}\text { Atribut } \\
\text { Kriteria }\end{array}$ \\
\hline C1 & Pendidikan & $15 \%$ & 0.15 & Benefit \\
\hline C2 & Kemampuan Membuat Pola & $20 \%$ & 0.2 & Benefit \\
\hline C3 & Pengalaman Kerja & $15 \%$ & 0.15 & Benefit \\
\hline C4 & Penguasaan Teknik Menjahit & $25 \%$ & 0.25 & Benefit \\
\hline C5 & Penggunaan Mesin Jahit & $25 \%$ & 0.25 & Benefit \\
\hline
\end{tabular}

a. Kriteria Pendidikan (C1)

Tabel 4. Kriteria Pendidikan

\begin{tabular}{|c|l|c|}
\hline No & \multicolumn{1}{|c|}{ Keterangan } & Bobot Kriteria \\
\hline 1 & SMK Tata Busana & 5 \\
\hline 2 & SMA + Kursus Menjahit & 4 \\
\hline 3 & SMP + Kursus Menjahit & 3 \\
\hline 4 & SD + Kursus Menjahit & 2 \\
\hline 5 & SMA & 1 \\
\hline
\end{tabular}

b. Kriteria Kemampuan Membuat Pola (C2)

Tabel 5. Kriteria Kemampuan Membuat Pola

\begin{tabular}{|c|l|c|}
\hline No & \multicolumn{1}{|c|}{ Keterangan } & Bobot Kriteria \\
\hline 1 & Mampu Membuat 4 Pola & 5 \\
\hline 2 & Mampu Membuat 3 Pola & 4 \\
\hline 3 & Mampu Membuat 2 Pola & 3 \\
\hline 4 & Mampu Membuat 1 Pola & 2 \\
\hline 5 & Tidak Mampu & 1 \\
\hline
\end{tabular}

c. Kriteria Pengalaman Kerja (C3)

Tabel 6. Kriteria Pengalaman Kerja

\begin{tabular}{|c|l|c|}
\hline No & \multicolumn{1}{|c|}{ Keterangan } & Bobot Kriteria \\
\hline 1 & Diatas 5 Tahun & 5 \\
\hline 2 & Diatas 3-4 Tahun & 4 \\
\hline 3 & Diatas 2-3 Tahun & 3 \\
\hline 4 & Diatas 1-2 Tahun & 2 \\
\hline 5 & 0-1 Tahun & 1 \\
\hline
\end{tabular}

d. Kriteria Penguasaan Teknik Menjahit (C4)

Tabel 7. Kriteria Penguasaan Teknik Menjahit

\begin{tabular}{|c|l|c|}
\hline No & \multicolumn{1}{|c|}{ Keterangan } & Bobot Kriteria \\
\hline 1 & Menguasai 4 Teknik Mnejahit & 5 \\
\hline 2 & Menguasai 4 Teknik Mnejahit & 4 \\
\hline 3 & Menguasai 4 Teknik Mnejahit & 3 \\
\hline
\end{tabular}

J-SISKO TECH Vol. 3, No. 2 Juli , $2020: 12-24$ 


\begin{tabular}{|c|l|c|}
\hline 4 & Menguasai 4 Teknik Mnejahit & 2 \\
\hline 5 & Tidak Menguasai & 1 \\
\hline
\end{tabular}

e. Kriteria Penggunaan Mesin Jahit (C5)

Tabel 8. Kriteria penggunaan Mesin Jahit

\begin{tabular}{|c|l|c|}
\hline No & \multicolumn{1}{|c|}{ Keterangan } & Bobot Kriteria \\
\hline 1 & Mampu Menggunakan 4 Mesin Jahit & 5 \\
\hline 2 & Mampu Menggunakan 3 Mesin Jahit & 4 \\
\hline 3 & Mampu Menggunakan 2 Mesin Jahit & 3 \\
\hline 4 & Mampu Menggunakan 1 Mesin Jahit & 2 \\
\hline 5 & Tidak Mampu & 1 \\
\hline
\end{tabular}

Tabel 9. Konversi Data Nilai Alternatif

\begin{tabular}{|c|c|c|c|c|c|c|c|}
\hline No & & Nama Pelamar & C1 & $\mathrm{C2}$ & C3 & C4 & C5 \\
\hline 1 & $(\mathrm{~A} 1)$ & Yulinda Sari & 2 & 2 & 5 & 2 & 2 \\
\hline 2 & (A2) & Asyifa Sholatul & 3 & 4 & 1 & 3 & 2 \\
\hline 3 & (A3) & Selia Jurius & 5 & 5 & 2 & 4 & 4 \\
\hline 4 & (A4) & Ayundari Nasution & 5 & 5 & 2 & 5 & 4 \\
\hline 5 & (A5) & Juraiya & 5 & 5 & 3 & 5 & 5 \\
\hline 6 & (A6) & Zuliana Hasanah Sari & 4 & 5 & 5 & 5 & 4 \\
\hline 7 & (A7) & Rika Situmeang & 5 & 4 & 3 & 3 & 5 \\
\hline 8 & (A8) & Meliyana Panjaitan & 4 & 5 & 4 & 3 & 4 \\
\hline 9 & (A9) & Adelia Santika & 4 & 4 & 2 & 4 & 4 \\
\hline 10 & (A10) & Mayra Septiana & 1 & 1 & 1 & 2 & 1 \\
\hline & & MAX & 5 & 5 & 5 & 5 & 5 \\
\hline
\end{tabular}

Berdasarkan analisa data diatas, berikut ini adalah langkah-langkah dalam penyelesaian proses perhitungan dengan metode WASPAS:

\section{Membuat Matriks Keputusan}

Berikut ini adalah matriks keputusan berdasarkan dari konversi data nilai alternatif:

$$
\boldsymbol{x}=\left[\begin{array}{lllll}
2 & 2 & 5 & 2 & 2 \\
3 & 4 & 1 & 3 & 2 \\
5 & 5 & 2 & 4 & 4 \\
5 & 5 & 2 & 5 & 4 \\
5 & 5 & 3 & 5 & 5 \\
4 & 5 & 5 & 5 & 4 \\
5 & 4 & 3 & 3 & 5 \\
4 & 5 & 4 & 3 & 4 \\
4 & 4 & 2 & 4 & 4 \\
1 & 1 & 1 & 2 & 1
\end{array}\right]
$$

\section{Menentukan Normalisasi Matriks}

Berikut ini adalah normalisasi matriks dari nilai alternatif sesuai dengan jenis kriterianya dengan ketentuan:

$$
X_{i j}=\frac{X_{i j}}{\operatorname{Max}_{i} X_{i j}}
$$


Kriteria Keuntungan :

Kriteria Biaya : $\quad X_{i j}=\frac{\operatorname{Min}_{i} X_{i j}}{X_{i j}}$

Normalisasi untuk kriteria I

$$
\begin{aligned}
& A_{11}=\frac{2}{5}=0.4 \\
& A_{21}=\frac{3}{5}=0.6 \\
& A_{31}=\frac{5}{5}=1 \\
& A_{41}=\frac{5}{5}=1 \\
& A_{51}=\frac{5}{5}=1
\end{aligned}
$$

$\mathrm{A}_{61}=\frac{4}{5}=0.8$

$\mathrm{A}_{71}=\frac{5}{5}=1$

$\mathrm{A}_{81}=\frac{4}{5}=0.8$

$\mathrm{A}_{91}=\frac{4}{5}=0.8$

$\mathrm{A}_{101}=\frac{1}{5}=0.2$

Normalisasi untuk kriteria II

$$
\begin{aligned}
& A_{12}=\frac{2}{5}=0.4 \\
& A_{22}=\frac{4}{5}=0.8 \\
& A_{32}=\frac{5}{5}=1 \\
& A_{42}=\frac{5}{5}=1 \\
& A_{52}=\frac{5}{5}=1
\end{aligned}
$$$$
A_{62}=\frac{5}{5}=1
$$$$
\mathrm{A}_{72}=\frac{4}{5}=0.8
$$$$
\mathrm{A}_{82}=\frac{5}{5}=1
$$$$
\mathrm{A}_{92}=\frac{4}{5}=0.8
$$$$
\mathrm{A}_{102}=\frac{1}{5}=0.2
$$

Normalisasi untuk kriteria III

$$
\begin{aligned}
& A_{13}=\frac{5}{5}=1 \\
& A_{23}=\frac{1}{5}=0.2 \\
& A_{33}=\frac{2}{5}=0.4 \\
& A_{43}=\frac{2}{5}=0.4 \\
& A_{53}=\frac{3}{5}=0.6
\end{aligned}
$$$$
A_{63}=\frac{5}{5}=1
$$$$
\mathrm{A}_{73}=\frac{3}{5}=0.6
$$$$
\mathrm{A}_{83}=\frac{4}{5}=0.8
$$$$
\mathrm{A}_{93}=\frac{2}{5}=0.4
$$$$
\mathrm{A}_{103}=\frac{1}{5}=0.2
$$

Normalisasi untuk kriteria IV

$$
\mathrm{A}_{14}=\frac{2}{5}=0.4
$$$$
\mathrm{A}_{64}=\frac{5}{5}=1
$$

$\mathrm{A}_{24}=\frac{3}{5}=0.6$

$\mathrm{A}_{74}=\frac{3}{5}=0.6$

$\mathrm{A}_{34}=\frac{4}{5}=0.8$

$\mathrm{A}_{84}=\frac{3}{5}=0.6$

$\mathrm{A}_{44}=\frac{5}{5}=1$

$\mathrm{A}_{54}=\frac{5}{5}=1$

$\mathrm{A}_{94}=\frac{4}{5}=0.8$

$\mathrm{A}_{104}=\frac{2}{5}=0.4$

Normalisasi untuk kriteria $\mathrm{V}$
$\mathrm{A}_{15}=\frac{2}{5}=0.4$
$A_{65}=\frac{4}{5}=0.8$
$\mathrm{A}_{25}=\frac{2}{5}=0.4$
$A_{75}=\frac{5}{5}=1$ 

$\mathrm{A}_{35}=\frac{4}{5}=0.8$
$\mathrm{A}_{85}=\frac{4}{5}=0.8$
$\mathrm{A}_{45}=\frac{4}{5}=0.8$
$A_{95}=\frac{4}{5}=0.8$
$A_{55}=\frac{5}{5}=1$
$\mathrm{A}_{105}=\frac{1}{5}=0.2$

Maka hasil normalisasi dari matriks keputusan secara keseluruhan adalah sebagai berikut:

$$
\boldsymbol{x}=\left[\begin{array}{ccccc}
0.4 & 0.4 & 1 & 0.4 & 0.4 \\
0.6 & 0.8 & 0.2 & 0.6 & 0.4 \\
1 & 1 & 0.4 & 0.8 & 0.8 \\
1 & 1 & 0.4 & 1 & 0.8 \\
1 & 1 & 0.6 & 1 & 1 \\
0.8 & 1 & 1 & 1 & 0.8 \\
1 & 0.8 & 0.6 & 0.6 & 1 \\
0.8 & 1 & 0.8 & 0.6 & 0.8 \\
0.8 & 0.8 & 0.4 & 0.8 & 0.8 \\
0.4 & 0.2 & 0.2 & 0.4 & 0.2
\end{array}\right]
$$

3. Menentukan Nilai Qi

Adapun rumus yang digunakan untuk menghitung Qi yaitu sebagai berikut:

$$
\begin{aligned}
& \mathrm{Qi}=0,5 \sum_{j=1}^{n} X i j w+0,5 \prod_{j=1}^{n}(x i j)^{w j} \\
& Q 1=0.5 \sum(0.4 * 0.15)+(0.4 * 0.20)+(1 * 0.15)+(0.4 * 0.25)+(0.4 * 0.25) \\
& =0.5(0.4900) \\
& =0.2450 \\
& =0.5 \Pi\left(0.4^{0.15 *} 0.4^{0.20 *} 1^{0.15 *} 0.4^{0.25 *} 0.4^{0.25}\right) \\
& =0.5(0.4589) \\
& =0,2295 \\
& =0.2450+0,2295 \\
& =0.4745 \\
& Q 2=0.5 \sum(0.6 * 0.15)+(0.8 * 0.20)+(0.2 * 0.15)+(0.6 * 0.25)+(0.4 * 0.25) \\
& =0.5(0.5300) \\
& =0.2650
\end{aligned}
$$

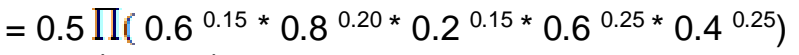

$$
\begin{aligned}
& =0.5(0.4870) \\
& =0,2435 \\
& =0.2650+0,2435 \\
& =0.5085 \\
& Q 3=0.5 \sum(1 * 0.15)+(1 * 0.20)+(0.4 * 0.15)+(0.8 * 0.25)+(0.8 * 0.25) \\
& =0.5(0.8100) \\
& =0.4050
\end{aligned}
$$

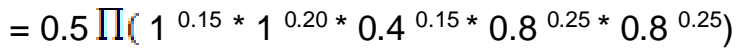

$$
\begin{aligned}
& =0.5(0.7796) \\
& =0,3898 \\
& =0.4050+0,3898 \\
& =0.7948
\end{aligned}
$$




$$
\begin{aligned}
& Q 4=0.5 \sum(1 * 0.15)+(1 * 0.20)+(0.4 * 0.15)+(1 * 0.25)+(0.8 * 0.25) \\
& =0.5(8600) \\
& =0.4300
\end{aligned}
$$

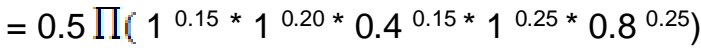

$$
\begin{aligned}
& =0.5(0.8243) \\
& =0,4121 \\
& =0.4300+0,4121 \\
& =0.8421 \\
& Q 5=0.5 \sum(1 * 0.15)+(1 * 0.20)+(0.6 * 0.15)+(1 * 0.25)+(1 * 0.25) \\
& =0.5(0.9400) \\
& =0.4700 \\
& =0.5 \Pi\left(1^{0.15 *} 1^{0.20 * 0.6} 6^{0.15 *} 1^{0.25 *} 1^{0.25}\right) \\
& =0.5(0.9262) \\
& =0,4631 \\
& =0.4700+0,4631 \\
& =0.9331 \\
& Q 6=0.5 \sum(0.8 * 0.15)+(1 * 0.20)+(1 * 0.15)+(1 * 0.25)+(0.8 * 0.25) \\
& =0.5(0.9200) \\
& =0.4600
\end{aligned}
$$

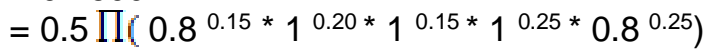

$$
\begin{aligned}
& =0.5(0.9146) \\
& =0,4573 \\
& =0.4600+0,4573 \\
& =0.9173 \\
& Q 7=0.5 \sum(1 * 0.15)+(0.8 * 0.20)+(0.6 * 0.15)+(0.6 * 0.25)+(1 * 0.25) \\
& =0.5(0.8000) \\
& =0.4000 \\
& =0.5 \Pi\left(1^{0.15 *} 0.8^{0.20 *} 0.6^{0.15 *} 0.6^{0.25 *} 1^{0.25}\right) \\
& =0.5(0.7796) \\
& =0,3898 \\
& =0.4000+0,3898 \\
& =0.7898 \\
& Q 8=0.5 \sum(0.8 * 0.15)+(1 * 0.20)+(0.8 * 0.15)+(0.6 * 0.25)+(0.8 * 0.25) \\
& =0.5(0.7900) \\
& =0.3950 \\
& =0.5 \Pi\left(0.8^{0.15 *} 1^{0.20 *} 0.8^{0.15 *} 0.6^{0.25 *} 0.8^{0.25}\right) \\
& =0.5(0.7785) \\
& =0,3892 \\
& =0.3950+0,3892 \\
& =0.7842 \\
& Q 9=0.5 \sum(0.8 * 0.15)+(0.8 * 0.20)+(0.4 * 0.15)+(0.8 * 0.25)+(0.8 * 0.25) \\
& =0.5(0.7400) \\
& =0.3700
\end{aligned}
$$

J-SISKO TECH Vol. 3, No. 2 Juli , 2020 : 12-24 


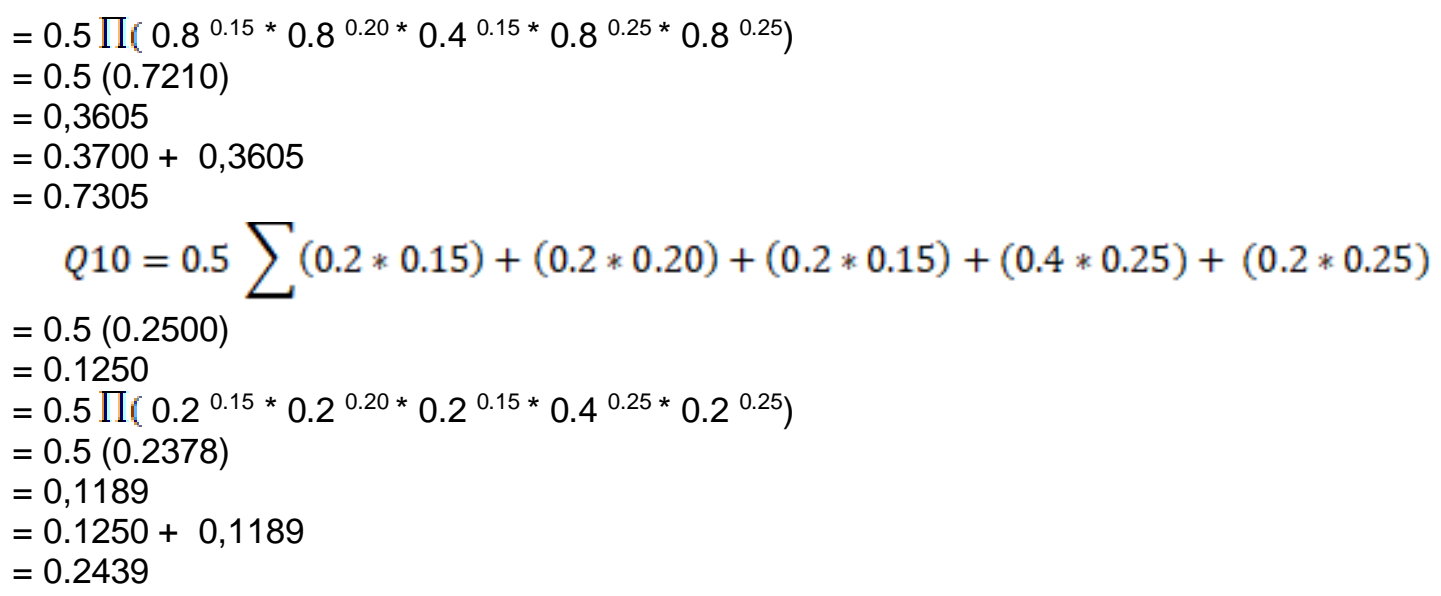

\section{Perangkingan}

Berdasarkan hasil perhitungan diatas maka dilakukan perangkingan nilai preferensi dari yang tertinggi hingga terendah dengan tabel dibawah ini:

Tabel 10. Hasil Perangkingan Metode WASPAS

\begin{tabular}{|c|c|c|c|}
\hline No & Nama & Qi & Rangking \\
\hline 1 & Yulinda Sari & 0.4745 & Rangking 9 \\
\hline 2 & Asyifa Sholatul & 0.5085 & Rangking 8 \\
\hline 3 & Selia Jurius & 0.7984 & Rangking 4 \\
\hline 4 & Ayundari Nasution & 0.8421 & Rangking 3 \\
\hline 5 & Juraiya & 0.9331 & Rangking 1 \\
\hline 6 & Zuliana Hasanah Sari & 0.9173 & Rangking 2 \\
\hline 7 & Rika Situmeang & 0.7898 & Rangking 5 \\
\hline 8 & Meliyana Panjaitan & 0.7842 & Rangking 6 \\
\hline 9 & Adelia Santika & 0.7305 & Rangking 7 \\
\hline 10 & Mayra Septiana & 0.2439 & Rangking 10 \\
\hline
\end{tabular}

Dari nilai preferensi diatas diperhitungkan bahwa $Q_{5}$ memiliki nilai terbesar, sehingga dapat disimpulkan bahwa alternatif yang bernama Juraiya adalah alternatif yang dipilih sebagai Calon Tailor (Penjahit) di Ranhouse Medan.

\subsection{Hasil}

Pada tahap hasilini, data yang digunakan adalah data hasil riset dalam memilih Calon Tailor (Penjahit) di Ranhouse Medan. Berikut di bawah tahap dari pengaplikasian aplikasi sistem pendukung keputusan dengan menggunakan metode Weighted Aggregated Sum Product Assesment (WASPAS) :

1. Form Menu Utama

Form menu utama merupakan tampilan yang akan muncul setelah admin melakukan login dan dirancang

untuk melengkapi sistem yang akan dibuat juga terhubung dengan form-form lainnya. 


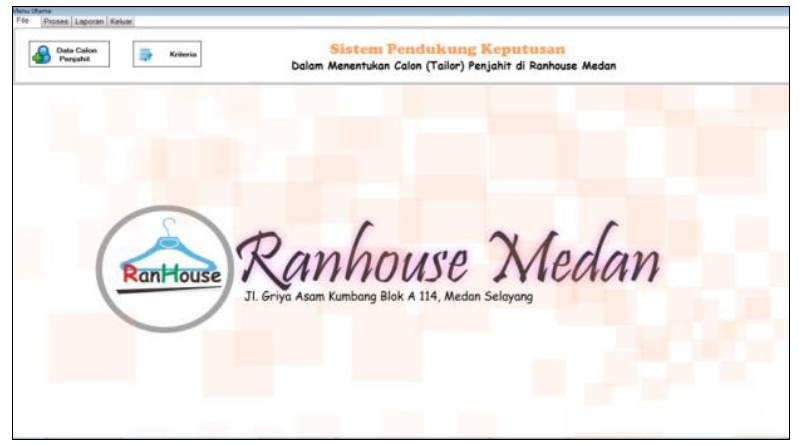

Gambar 1. Tampilan Form Interface

2. Form Data Calon Tailor Penjahit

Form data calon tailor (penjahit) merupakan form yang digunakan untuk meng-input data calon penjahit di Ranhouse Medan. Di bawah ini merupakan tampilan form input data calon tailor (penjahit) sebagai berikut :

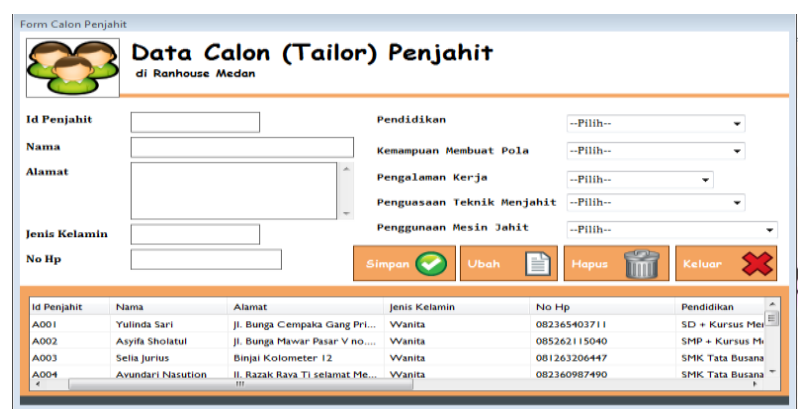

Gambar 2. Tampilan Form Data Calon Tailor (Penjahit)

\section{Form Kriteria}

Form data kriteria merupakan form yang digunakan untuk meng-input data kriteria yang ada pada Ranhouse Medan. Berikut adalah tampilan form input data kriteria:

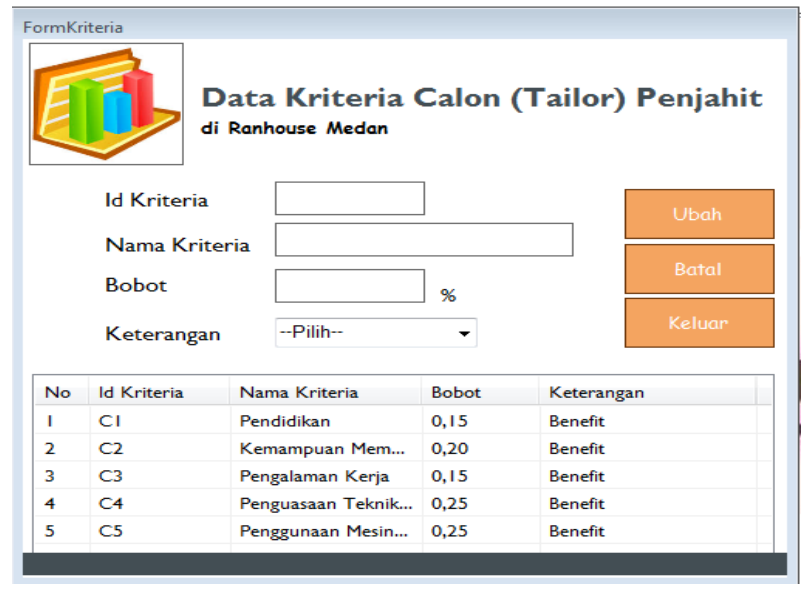

Gambar 3. Tampilan Form Kriteria

J-SISKO TECH Vol. 3, No. 2 Juli , 2020 : 12-24 
4. Form Proses Perhitungan WASPAS

Form ini akan melakukan proses Perhitungan dengan Metode Weighted Aggregated Sum Product Assesment (WASPAS) yang akan diproses atau dihitung berdasarkan nilai kriteria dari tailor (penjahit) yang telah dibobotkan. Berikut adalah tampilan Form Perhitungan:

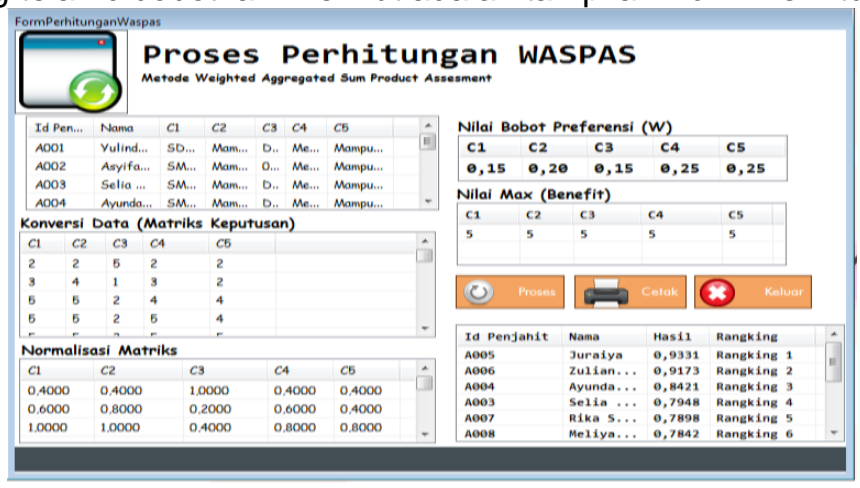

\section{Gambar 4. Tampilan Form Proses Perhitungan WASPAS}

\section{Form Laporan}

Form Laporan hasil merupakan tampilan dari laporan dalam menentukan calon tailor (penjahit) yang memiliki nilai tertinggi pada Ranhouse Medan adalah sebagai berikut:

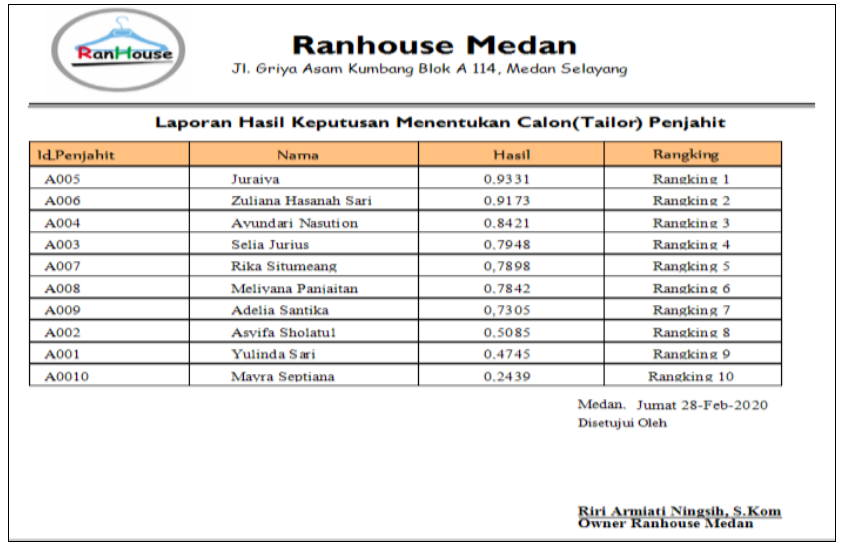

Gambar 5. Tampilan Form Laporan

\section{Kesimpulan}

Berdasarkan penelitian yang telah dilakukan sistem pendukung keputusan dalam menentukan Calon Tailor (Penjahit) dengan menggunakan metode WASPAS maka dapat disimpulkan bahwa:

1. Pemilihan Calon Tailor (Penjahit) dapat diselesaikan dengan metode weighted aggregated sum product assesment.

2. Perancangan sistem yang dilakukan dengan menganalisa sistem dan kebutuhan sistem.

3. Pengimplementasian dan pengujian sistem yang sudah dirancang dengan menambahkan alternatif baru dan melihat hasil dari aplikasi tersebut. 


\section{REFERENSI}

[1] T. A. Surya, F. I. Kreatif, And U. Telkom, "PERANCANGAN WORKSTATION UNTUK KEGIATAN MENJAHIT DI RUMAH," Vol. 4, No. 3, Pp. 1494-1500, 2017.

[2] Kusrini, Konsep Dan Aplikasi Sistem Pendukung Keputusan, Andi. Yogyakarta, 2014.

[3] A. K. Hidayah And Y. Erwadi, "Sistem Pendukung Keputusan Pemilihan Ketua Badan Eksekutif Mahasiswa Dengan Metode Simple Additive Weighting," Vol. 2, Pp. 92-96, 2019.

[4] A. Safitra, I. A. Lubis, And N. Siregar, "Sistem Pendukung Keputusan Pemilihan Games Untuk Remaja Menggunakan Metode WASPAS," Pp. 141-147, 2018.

[5] S. Barus, V. M. Sitorus, And D. Napitupulu, "Sistem Pendukung Keputusan Pengangkatan Guru Tetap Menerapkan Metode Weight Aggregated Sum Product Assesment ( WASPAS )," Vol. 2, No. 2, Pp. 10-15, 2018. 